\title{
InP DHBT MMICs for millimeter-wave front-ends
}

\author{
Johansen, Tom Keinicke; Hadziabdic, Dzenan; Krozer, Viktor
}

Published in:

SBMO/IEEE MTT-S International Microwave and Optoelectronics Conference (IMOC)

Link to article, DOI:

10.1109/IMOC.2009.5427464

Publication date:

2009

Document Version

Publisher's PDF, also known as Version of record

Link back to DTU Orbit

Citation (APA):

Johansen, T. K., Hadziabdic, D., \& Krozer, V. (2009). InP DHBT MMICs for millimeter-wave front-ends. In SBMO/IEEE MTT-S International Microwave and Optoelectronics Conference (IMOC) IEEE. https://doi.org/10.1109/IMOC.2009.5427464

\section{General rights}

Copyright and moral rights for the publications made accessible in the public portal are retained by the authors and/or other copyright owners and it is a condition of accessing publications that users recognise and abide by the legal requirements associated with these rights.

- Users may download and print one copy of any publication from the public portal for the purpose of private study or research.

- You may not further distribute the material or use it for any profit-making activity or commercial gain

- You may freely distribute the URL identifying the publication in the public portal

If you believe that this document breaches copyright please contact us providing details, and we will remove access to the work immediately and investigate your claim 


\title{
InP DHBT MMICs for Millimeter-Wave Front-ends
}

\author{
Tom K. Johansen, Dzenan Hadziabdic, Viktor Krozer \\ DTU Elektro. Technical University of Denmark \\ Kgs. Lyngby, Denmark \\ tkj@elektro.dtu.dk
}

\begin{abstract}
In this paper, we show advanced MMIC's using InP DHBT technology. In particular, we demonstrate front-end circuits covering a broad frequency range from Q-band to Eband. Realizations of power amplifiers, quadrature VCOs, and sub-harmonic mixers, are presented and experimental results are discussed.
\end{abstract}

Heterojunction bipolar transistors (HBTs); millimeter-wave circuit; monolithic microwave integrated circuit (MMIC)

\section{INTRODUCTION}

Millimeter-wave technology is important for emerging multi Gigabit/s networks such as E-band wireless communication. These high-capacity networks are believed to partly substitute optical fiber based network in the near future. In this paper, we show advanced MMIC's using InP DHBT technology. Our main motivation is the high breakdown voltage of the InP DHBT technology at mm-wave frequencies especially important for power amplifiers. This is illustrated in Figure 1 which compares SiGe HBT, InP HEMT, and InP HBT technologies, respectively. As can be depicted from the figure, cut-off frequencies of InP HBT and HEMT devices reach similar values on individual transistor level. However, HEMT based MMIC at high frequencies are much more mature. This phenomenon can be attributed to the fact that most HBT based circuits at these frequencies have been designed with digital applications in mind, whereas HEMT technologies have been successfully employed in mm-wave front-end circuits for years.

The technology employed in this paper has been developed at the III-V Lab in Marcoussis, France and has been successfully applied to optical communication circuits. The InP DHBT devices in this mature circuit oriented technology exhibits cut-off frequencies of $200 \mathrm{GHz}$ with breakdown voltages of $7 \mathrm{~V}$ [1]. Besides power amplifiers other mm-wave front-end circuits such as VCOs, frequency multipliers, and sub-harmonic mixers can equally well be implemented in InP DHBT technology. Here, we present a series of MMIC designs aimed at the realization of a full $\mathrm{mm}$-wave front-end. Though our focus is on development of a chip-set for emerging E-band wireless communication some Q-band MMICs are also presented in this paper. The design principles employed for these circuits, however, are easily frequency scaled to E-band frequencies.

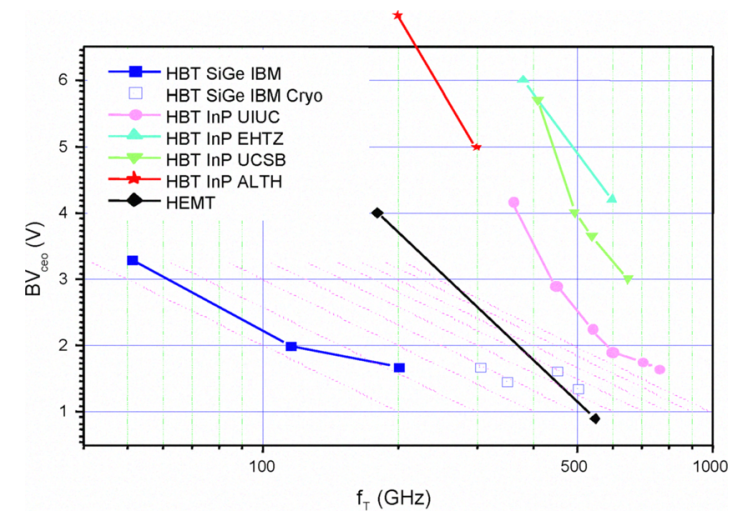

Figure 1: Breakdown voltage versus cut-off frequency for different technologies

\section{E-BAND POWER AMPLIFER}

We have already reported on the capabilities of this technology for power amplifier at E-band frequencies around 71-76 GHz [2]. The configuration of the power amplifier shown in figure 2 is based on a driver stage and a power stage. Both the driver and the power stage consist of two thermally stable power cells of each $4 \times 1.5 \times 10 \mu \mathrm{m}^{2}$ HBT devices. The stability has been checked with transient simulations, especially exciting an odd-mode signal. The circuit was initially sensitive to odd-mode excitation between the two driver stages, which was eliminated using an odd mode resistor in the driver stage.

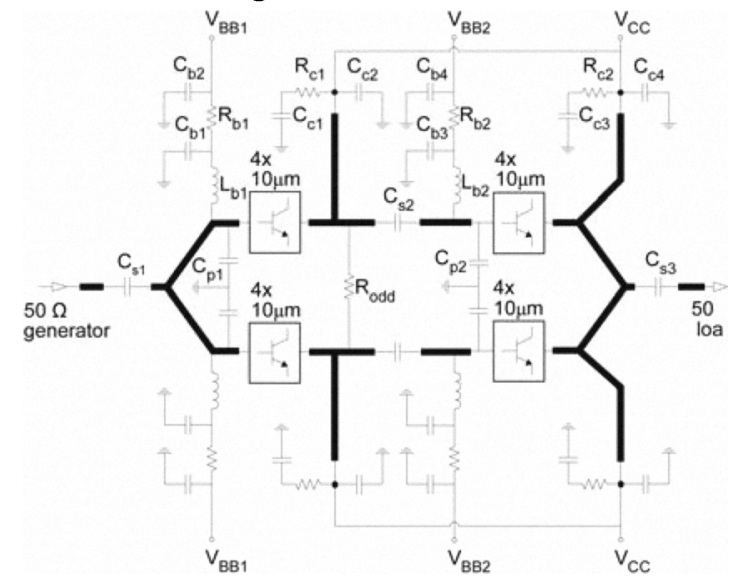

Figure 2: Power amplifier schematic. 


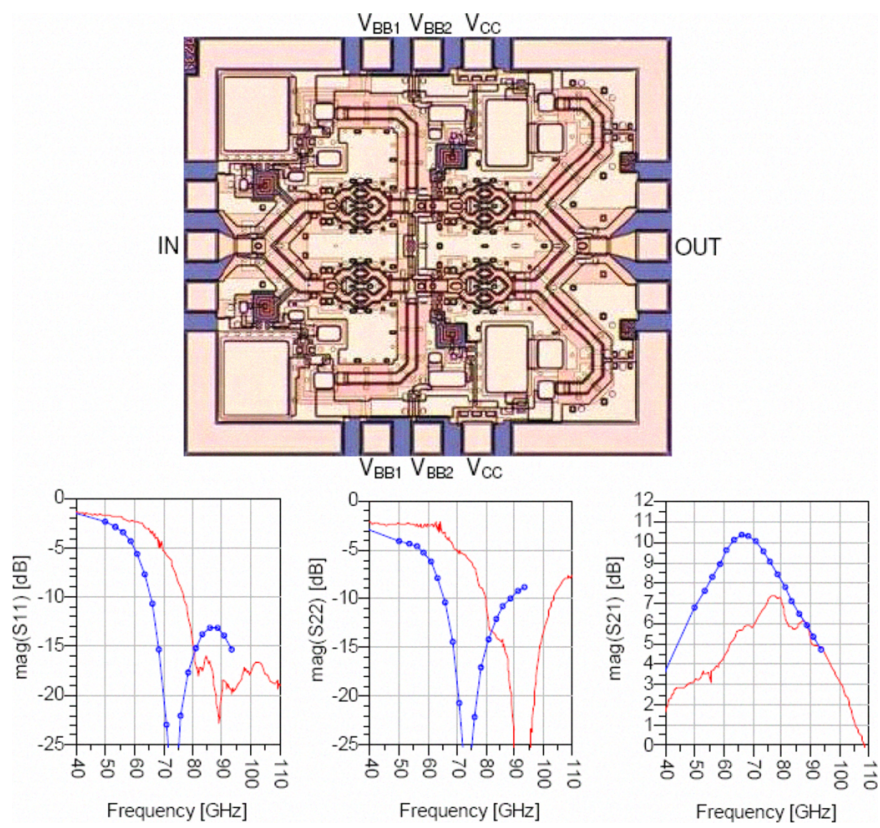

Figure 3: E-band power amplifier. Top: microphotograph; Bottom: comparison between measured (symbols) and simulated (solid line) small-signal results of the E-band power amplifier.

Small-signal measurements are shown in Figure 3. One can depict that the performance is shifted towards higher frequencies, probably due to inaccurate determination of the matching line length. The power amplifier has been predicted to deliver $20 \mathrm{dBm}$ linear output power fulfilling the stringent E-band specifications. Currently, the circuit is being characterized in terms of power. Lower output power than predicted from circuit simulations is expected due to the reduced gain.

\section{QUADRATURE VCO}

A quadrature VCO with record high frequency of oscillation has been reported in [3]. It is based on crosscoupled pairs of oscillators with buffer stages as shown in figure 4. Care has been taken to avoid parasitic oscillations of the buffer transistors. This topology has the advantage of creating a balanced quadrature signal suitable for direct excitation of an E-band sub-harmonic mixer of the stacked Gilbert cell topology if sufficient power level is obtained.

As shown in figure 5, the measured output power is around $-15 \mathrm{dBm}$ across a frequency range of $38-48 \mathrm{GHz}$, yielding a frequency tuning sensitivity of around $8 \mathrm{GHz} / \mathrm{V}$. The power consumption is $120-172 \mathrm{~mW}$ for the quadrature VCO including the buffers. The high sensitivity gives rise to a fairly large phase-noise contribution. This sensitivity can be decreased by controlling the current at the current sources of the switching stages. The highest frequency is limited by interconnect parasitics and can in principle reach beyond Qband frequencies for this topology.

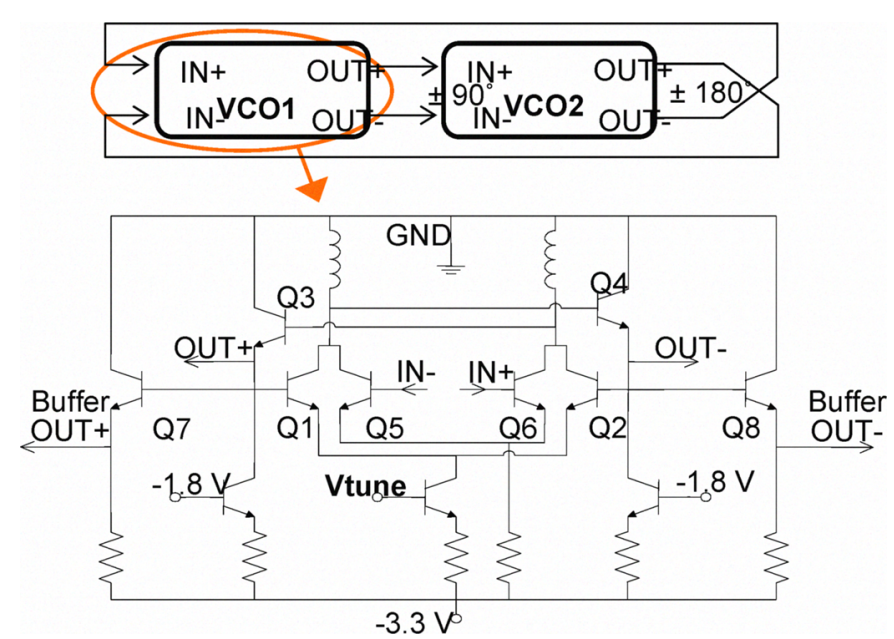

Figure 4: Schematic of quadrature VCO.

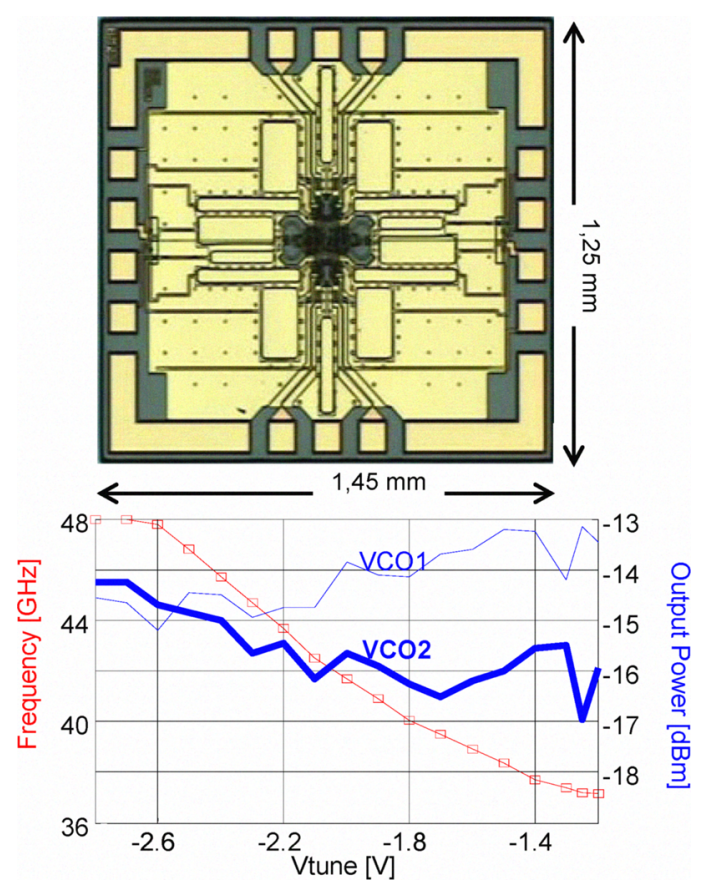

Figure 5: Quadrature VCO for an E-band sub-harmonic mixer. Top: microphotograph; Bottom: output power and operating frequency versus tuning voltage.

\section{Q-BAND SUB-HARMONIC MIXER}

At mm-wave frequencies sub-harmonic mixers offer the advantage of lower LO frequency and natural isolation for the input LO signal. Most of the sub-harmonic mixers today are based on diodes and only limited number of mixer realizations have been published using HBT based technologies. We have already reported on an excellent Q-band sub-harmonic mixer exhibiting conversion gain of $G_{c o n v}=10 \mathrm{~dB}$ with an input LO 
power level of $P_{L O}=1 \mathrm{~mW}$ [4]. Here, we present a novel balanced Q-band sub-harmonic mixer with miniature Marchand balun.

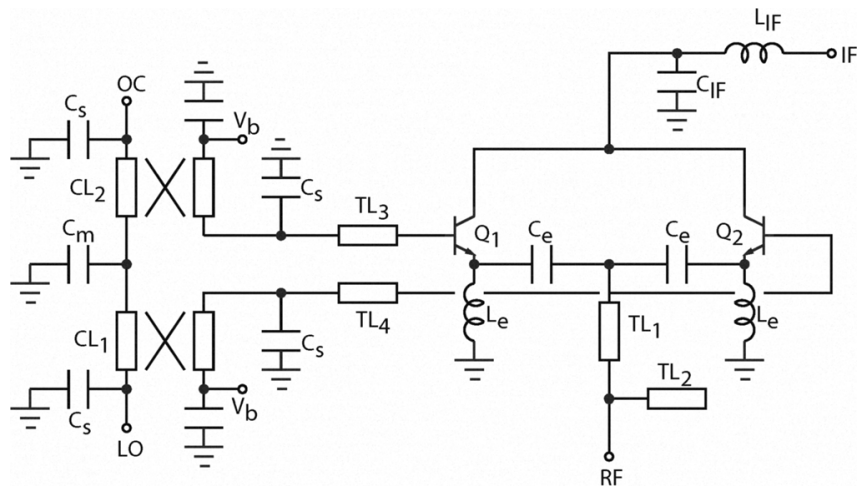

Figure 6 Schematic of Q-band sub-harmonic mixer with miniature Marchand balun.

Figure 6 shows the schematic of the sub-harmonic mixer including the miniature Marchand balun for out-of-phase LO excitation of $Q_{1}$ and $Q_{2}$. The balun consists of two coupled line sections implemented as broadside coupled spiral type transformers. The shunt capacitors are added for size reduction. The analysis and design procedure of this miniature Marchand balun was reported previously by the authors in [5].

The microphotograph of the fabricated Q-band subharmonic mixer with miniature Marchand balun is shown in figure 7. Figure 8 shows the measured conversion gain versus $\mathrm{RF}$ frequency. A conversion loss of only $2.1 \mathrm{~dB}$ at an RF frequency of $41 \mathrm{GHz}$ is demonstrated with an associated $\mathrm{LO}$ power level of $5 \mathrm{dBm}$. The DC power consumption of the subharmonic mixer is as low as $22.5 \mathrm{~mW}$ under normal operation. The LO-IF isolation is $>45 \mathrm{~dB}$ across a frequency span from $33-50 \mathrm{GHz}$. We believe this is owing to the excellent performance of the Marchand balun employed in the circuit. This is furthermore verified by measurements on the miniature Marchand balun as a stand-alone test structure. E-band subharmonic mixers based on the same topology have also been realized and are currently being tested. Experimental results should be available at the time of the conference.

\section{CONCLUSIONS}

In summary, we have demonstrated a number of MMIC realisations for the Q-band and E-band which show the promising properties of InP HBT technology. The circuits demonstrated take full advantage of the HBT technology and indicate that InP HBT technology provides a good alternative for high breakdown voltage high performance MMIC at mmwave frequencies.

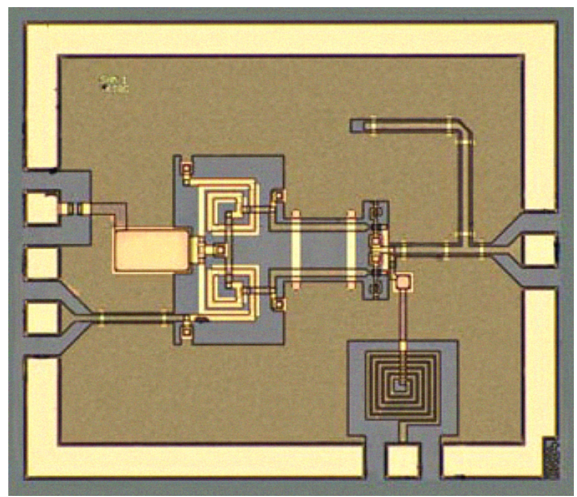

Figure 7: Microphotograph of fabricated Q-band subharmonic mixer with miniature Marchand balun

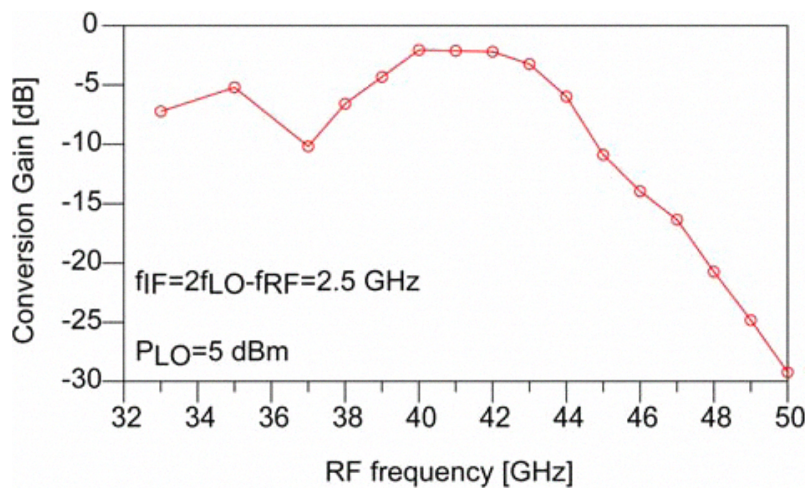

Figure 8: Measured conversion gain versus RF frequency.

\section{ACKNOWLEDGMENT}

The authors would like to acknowledge the III-V lab in Marcoussis, France for making the chip fabrication possible.

\section{REFERENCES}

[1] S. Blayak et al., MSI InP/InGaAs DHBT technology: beyond 40 Gbit/s circuits, in 14th Indium Phosphide and Related Materials Conference, pp. 51-54, 2002.

[2] D. Hadziabdic, V. Krozer, and T. K. Johansen, Power Amplifier Design for E-band Wireless System Communications, EuMC 2008, pp. 1378-1381, 2008.

[3] D. Hadziabdic, T. K. Johansen, V. Krozer, A. Konczykowska, M. Riet, F. Jorge, and J. Godin, A 47.8 GHz InP HBT quadrature VCO with $22 \%$ tuning range, Electronic Letters, vol. 43, no. 3, pp. 153-154, 2007

[4] T. K. Johansen et al., A High Conversion-Gain Q-Band InP DHBT Subharmonic Mixer Using LO Frequency Doubler, IEEE Trans. Microwave Theory and Tech., vol 56, no 3., pp 613-619, 2008

[5] T. K. Johansen and V. Krozer, Analysis and Design of Lumped Element Marchand Baluns, $17^{\text {th }}$ International Conference on Microwaves, Radars, and Wireless Communication, 2008. 